hypothyroid patients included two with cord damage and one with an unacceptable scar. It is of interest that in the group of four patients with postoperative tetany two showed objective evidence of cord damage. This association of hypoparathyroidism and recurrent laryngeal nerve damage has been pointed out by Shearman et al. (1965) and is clearly related to the extent of gland mobilization at operation.

The present findings add to the information on the long-term results of subtotal thyroidectomy for thyrotoxicosis. Thyroidectomy is an effective treatment for this serious disease. It shares this role with ${ }^{131} \mathrm{I}$ therapy. Comparisons of these two forms of treatment are inevitable and necessary. On the basis of such comparisons Green and Wilson (1964) and Byrd et al. (1960) have favoured surgery, while Bowers (1965) was less certain. Block (1967), in a recent review, indicates the need for offering therapy on an individual basis and against the background of services available-for example, a skilled thyroidectomist and local laboratory facilities. In either case long-term surveillance is necessary. As regards ${ }^{131} I$ therapy this surveillance may be more simple in that there appears to be only the one but not unlikely complication-namely, hypothyroidism. Surgery offers a greater chance of establishing a permanent euthyroid state, though the range of possible long-term complications is wider and less predictable.
We wish to thank Mr. R. B. Wright, senior surgeon, Southern General Hospital, Glasgow, who initiated this review and provided helpful criticism. We are indebted to Professor E. M. McGirr, University Department of Medicine, Glasgow Royal Infirmary, and Dr. W. S. T. Thomson, biochemist, Southern General Hospital, for providing laboratory facilities to Drs. R. Miller and I. J. Kerr, of the ear, nose, and throat department, Victoria Infirmary, Glasgow, who carried out the laryngoscopies.

\section{REFERENCES}

Asper, S. P. (1960). Arch. intern. Med., 106, 878.

Block, M. A. (1967). Surg. Gynec. Obstet., 125, 1083.

Bowers, R. F. (1965). Ann. Surg., 162, 478.

Byrd, B. F., McElhannon, F. M., and Dalton, J. B. (1960). Ann. Surg., 151,669 .

Green, M., and Wilson, G. M. (1964). Brit. med. f., 1, 1005.

Lancet, 1966, 1, 81.

McGirr, E. M., Thomson, J. A., and Murray, I. P. C. (1964). Scot. med. 7., 9, 505 .

McLean, F. C., and Hastings, A. B. (1935). Amer. F. med. Sci., 189, 601.

Roy, A. D., Allan, J., and Harden, R. McG. (1967). Lancet, 2, 684.

Shearman, B. T., Clubb, J. S., Neagle, F. C., and Posen, S. (1965). Brit. med. \%, 2, 619.

Wade, J. S. H. (1960-1). Brit. 3. Surg., 48, 25.

Wilkinson, R. H. (1957). \%. clin. Path., 10, 126.

Wilson, G. M. (1967). Symposium on Thyroid Disease and Calcium Metabolism, p. 51. Edinburgh.

\title{
Role of Mites in Allergy to House Dust
}

\section{H. MORROW BROWN,* M.D., F.R.C.P.ED. ; JOHN L. FILER, † M.B., CH.B.}

Brit. med. I., 1008, 3, 646-647

\begin{abstract}
Cummary : One hundred and thirty-two patients known or suspected of allergy to house dust were skintested with pure extracts of four varieties of dust mites. The results show that both Dermatophagoides culinae and D. pteronyssinus probably played important parts in sensituzing - susceptlbte people, as did Glycyphagus destructor and $\mathbf{G}$. domesticus in some cases. In some patients these results enabled successful desensitization against the dust to be carried out, and for corticosteroid therapy to be stopped. Hence the use of mite extracts is considered to be an important advance in the diagnosis of allergy to house dust.
\end{abstract}

\section{Introduction}

The researches of Voorhorst et al. (1967) in Holland directed attention to mites as the prime factor in house-dust allergy, and particularly to one species, Dermatophagoides pteronyssinus, as the source of the antigen. This work stimulated an interest in other mites inhabiting house dust, such as Glycyphagus destructor and Acarus siro, particularly by Pepys et al. (1968) and Feinberg and Hill (1968). Both have concentrated their attention on the closely related $D$. culinae, which is much easier to breed in the laboratory; and the latter also investigated $G$. destructor and $G$. domesticus, which have been found in abundance in some houses of asthmatic patients in the Trent River Valley where the terrain is low-lying and flat with a network of canals, giving conditions not dissimilar to those in the Netherlands.

\section{Materials and Methods}

Since October 1967, when pure mite extracts first became available for experimental purposes, patients known or suspected

\footnotetext{
* Consultant Chest Physician.

$t$ Medical Registrar.

Derwent Hospital and Derby Chest Clinic, Derby.
}

to be sensitive to house dust were skin-tested with the available extracts. Dome Laboratories house-dust extract for prick testing was used for comparison and for nasal provocation testing. All extracts were coded to avoid observer bias, and many different batches were tested for potency, some standardized in protein nitrogen units (P.N.U.), and others on a weight/ volume basis. Made up in $50 \%$ glycerol saline the material has remained stable at room temperature for over six months.

The mites were grown on dog-meal with added yeast, and the extracts were essentially free from antigens derived from the culture medium. Control tests with extracts of culture medium were invariably negative (Feinberg and Hill, 1968).

\section{Results}

The results of skin-testing with four varieties of mite extract are given in Table I. Four cases were positive for $D$. culinae but negative for $D$. pteronyssinus, the reactions to the latter being generally less intense. $D$. pteronyssinus was never positive when $D$. culinae was negative, but three cases gave a good positive for crude dust extract when all the mite extracts were negative, suggesting sensitivity to other allergens in the dust. Reactions to $G$. destructor were sometimes intense, while those to $G$. domesticus were seldom markedly positive.

In many cases skin reactions resembled those to grass pollen in intensity, particularly to $D$. culinae, the weal diameter often being 5 to $8 \mathrm{~mm}$., and the flare 25 to $35 \mathrm{~mm}$. Clear-cut specificity of skin-test response was frequently seen to different species of mites.

TABLB I.-Prick-test Results From Different Mite Extracts

\begin{tabular}{|c|c|c|c|c|c|}
\hline Prick Test & $\begin{array}{c}\text { House } \\
\text { Dust }\end{array}$ & D. culinae & $\begin{array}{c}\text { D. pteronys- } \\
\text { sinus }\end{array}$ & $\begin{array}{c}G . \\
\text { destructor }\end{array}$ & $\begin{array}{c}\boldsymbol{G} . \\
\text { domesticus }\end{array}$ \\
\hline $\begin{array}{ll}\text { Positive .. } & \ldots \\
\text { Negative } & \ldots \\
\text { No. of patients. }\end{array}$ & $\begin{array}{r}97 \\
35 \\
132\end{array}$ & $\begin{array}{r}127 \\
5 \\
132\end{array}$ & $\begin{array}{l}76 \\
13 \\
89\end{array}$ & $\begin{array}{r}47 \\
85 \\
132\end{array}$ & $\begin{array}{l}27 \\
20 \\
47\end{array}$ \\
\hline
\end{tabular}


Comparative titration of the skin sensitivity was therefore attempted with serial threefold dilutions of each extract by the prick method on the skin of the back. The results are shown in Table II, but do not really express to the full the dramatic and specific nature of the reactions.

TABLE II.-Comparative Skin-test Titrations in 27 House-dust-sensitive

\begin{tabular}{|c|c|c|c|c|c|c|}
\hline \multirow{2}{*}{ Extracts used for Prick Test } & \multirow{2}{*}{$\frac{\text { Undiluted }}{\text { Negative }}$} & \multicolumn{5}{|c|}{$\begin{array}{l}\text { Numbers Positive down to } \\
\text { each dilution. }\end{array}$} \\
\hline & & $1 / 1$ & $1 / 3$ & $1 / 9$ & $1 / 27$ & $1 / 81$ \\
\hline $\begin{array}{l}\text { D. culinae } 1,500 \text { P.N.U. ... } \\
\text { D. culinae } 0.1 \% \text { w/v } \\
\text { D. pteronyssinus } 0.1 \% \text { w/v } \\
G . \text { destructor } 0 \cdot 1 \% \text { w/v } \\
G . \text { domesticus } 1,500 \text { P.N.U. } \\
\text { House dust (Dome) } 10,000 \text { P.N. }\end{array}$ & $\begin{array}{r}2 \\
2 \\
3 \\
15 \\
8 \\
-\end{array}$ & $\begin{array}{l}3 \\
4 \\
1 \\
2 \\
8 \\
5\end{array}$ & $\begin{array}{r}4 \\
12 \\
12 \\
4 \\
8 \\
14\end{array}$ & $\begin{array}{r}12 \\
8 \\
10 \\
2 \\
3 \\
7\end{array}$ & $\begin{array}{r}4 \\
1 \\
1 \\
.1 \\
1\end{array}$ & $\frac{2}{3}$ \\
\hline
\end{tabular}

\section{Examination of Dust from Patients' Homes}

Ninety-five samples of dust from patients' homes were examined for the presence of mites. With a flotation method 21 samples were found to contain mites. Sixty-four of the 95 samples were also examined with the lactic acid method described by Spieksma (1967) and mites were found in 44 of these. Twenty-one were identified as Dermatophagoides species, six as Glycyphagus species.

A man aged 28, dependent on corticosteroids for 10 years, in whom all attempts to determine the cause of his asthma had been unsuccessful, was found to have intense reactions to $D$. culinae, $D$. pteronyssinus, and $G$. destructor. His home, built only five years ago and centrally heated, had no furniture older than the house, but with the help of Mr. A. M. Cunnington of the Pest Infestation Laboratory it was found to be heavily infested with $D$. pteronyssinus and $G$. destructor. A dust specimen from his mattress yielded a count of no fewer than $2,270 \mathrm{D}$. pteronyssinus per gramme of dust, yet the house was apparently immaculate.

\section{Discussion}

These results show that extracts of $D$. culinae are very active in skin-testing of house-dust-sensitive patients, there being almost complete correlation with extracts of $D$. pteronyssinus. It is apparent that members of the genus Glycyphagus may also be important in sensitizing susceptible individuals, and it is not improbable that other varieties of mite inhabiting house dust may also be found important.

The development of these testing extracts, with particular reference to $D$. culinae, represents a significant diagnostic advance. A review of the 132 cases tested showed that in 92 of them allergy to house dust had not been seriously considered as an important allergen. In many patients the picture was confused by multiple sensitivities, and the skin test to dust extract was rather unimpressive but very striking to mite extracts. In almost half the cases there was no history to suggest house-dust sensitivity, especially in children, but nasal provocation tests were all positive.

Perhaps the most important contribution is that these testing materials have led to the successful hyposensitization of patients with house-dust allergens, and some patients no longer require steroid therapy after being dependent for years (Brown, 1968).

For their invaluable assistance in making this investigation possible, we wish to thank Dr. J. G. Feinberg, D.V.M. Director of Research, who supplied the mite extracts ; Mrs. Christine Hill, who examined the dust samples and prepared the extracts of mites-of Dome Laboratories, Stoke Poges; and Mr. A. M. Cunnington, of the Pest Infestation Laboratory, Slough, who subjected some samples of dust to intensive analysis.

\section{REFERENCES}

Brown, H. M. (1968). British Tuberculosis Association Meeting, University of Keele, April 1968.

Feinberg, J. G., and Hill, C. (1968). To be published.

Pepys, J., Chan, Moira, and Hargreave, F. E. (1968). Lancet, 1, 1270 Spieksma, F. Th. M. (1967). Int. Rhinol., 5, 162

Voorhorst, R., Spieksma, F. Th. M., Varekamp, H., Leupen, M. J., and Lyklema, A. W. (1967). F. Allergy, 39, 325.

\title{
Plasma Amino-acids in the Nigerian Nutritional Ataxic Neuropathy
}

\author{
B. O. OSUNTOKUN,* M.B., B.S., M.R.C.P.; J. E. DUROWOJU, $†$ F.M.I.I.T. \\ H. MCFARLANE, $\dagger$ M.SC., PH.D.; J. WILSON, $\ddagger$ M.B., PH.D., M.R.C.P.
}

Summary : Investigation of nine patients with tropical ataxic neuropathy showed an absence or diminution of sulphur-containing amino-acids-cysteine and methionine-and a variable concentration of most other essential amino-acids. The pattern was unlike that found in kwashiorkor. The levels of serum cholesterol and total protein were normal, and the serum vitamin $B_{12}$ levels were normal or high. Plasma thiocyanate concentration was high.

All the patients gave a history of a monotonous diet of cassava derivatives. Cassava contains a cyanogenetic glycoside (linamarin) from which cyanide is released on hydrolysis. The excessive cyanide detoxication may be responsible for the low concentration of the sulphurcontaining amino-acids.

\footnotetext{
- Department of Psychiatry and Neurology, University College Hospital,

† Department of Chemical Pathology, University College Hospital, ₹ M.R.C. Clinical Genetics Research Unit, Institute of Neurology,
Queen's Square, London W.C.1.
}

\section{Introduction}

A chronic degenerative neuropathy, known as tropical or nutritional ataxic neuropathy (Money, 1959; Moore, 1966 ; Osuntokun, 1968), is common in Southern Nigeria in areas where the staple diet consists of cassava or its derivatives. Cassava is the tuber of manioc, a shrub introduced from South America early this century and widely grown since then as a heavy biannual crop because of its ease of cultivation. The Jamaican neuropathy extensively documented by Montgomery et al. (1964) is similar in certain respects to the Nigerian disease, but differs in some significant details (Monekosso, 1962). An acute retrobulbar neuritis developing in West African schoolchildren may represent an ingravescent form of this condition, which is usually found in adults.

Moore (1930, 1932, 1933a, 1933b), who first described the visual disorders in children, thought it might be related to riboflavine deficiency and emphasized the accompanying angular stomatitis, glossitis, facioscrotal seborrhoea, and dermatitis. He also observed that these disappeared when the visual acuity improved after treatment with Marmite, which is rich in ribo- 